\title{
Direct Bilirubin Measurement
}

National Cancer Institute

\section{Source}

National Cancer Institute. Direct Bilirubin Measurement. NCI Thesaurus. Code C64481.

The bilirubin is bound to glucuronide to form conjug ated bilirubin (direct bilirubin). Direct Bilirubin measurement is accomplished by a colorimetric method. Direct Bilirubin in biological fluids reacts with sulfanilic acid at acidic $\mathrm{pH}$ to produce a red colored complex. The optical density of produced color has a direct relationship with Direct Bilirubin concentration in the solution. 